\title{
Harmful Postures and Musculoskeletal Symptoms Among Fish Trimmers of a Fish Processing Factory in Ghana: A Preliminary Investigation
}

\author{
Reginald Quansah
}

\section{Department of Human Work Sciences, Luleå University of Technology, Luleå, Sweden}

This study investigated musculoskeletal symptoms among fish trimmers (skinners and polishers) in a fish processing factory in Ghana. The methods used included administration of questionnaire, walk through observation, interview, task analysis and future workshop. All 50 female participants answered and submitted their questionnaires. Of the 11 operations performed by skinners only 1 was rated as low risk. Also of the 12 operations performed by polishers only 2 were rated as low risk. Neck side bending, neck flexion, prolonged standing, shoulder elevation, abducted arms, repetitious reaching forward and wrist deviation were observed in most operations. This corresponds with questionnaire results in which musculoskeletal symptoms were mostly prevalent in the neck, the shoulder, the low back, the wrist/hand and the knee regions. There was no significant correlation $(\mathrm{p}<.05)$ between musculoskeletal symptoms and age, working hours and length of service. Task redesign, workplace changes and worker training were suggested to improve the work.

posture fish trimmers fish processing industry Ghana

\section{INTRODUCTION}

Early health problems identified in the fish processing industry include fatigue, stress, insomnia, digestive problems, and aches and pains. These health problems were associated with job satisfaction, physical environmental stressors and high work pace [1]. Since then, musculoskeletal disorders have been a top priority in the industry. The prevalence of sick leave due to disorders of the musculoskeletal system and the intention to leave the job due to musculoskeletal injuries were reportedly higher among the workers than the general population $[2,3]$. Former employees were also reported to have suffered 3 to 7 times more musculoskeletal injuries than current employees and this was their reason for quitting the job [4]. Prevalence of neck, shoulder, elbow and hand disorders have also been reported as higher in workers of the fish processing industry than the general population $[4,5,6]$. Most recent studies have also identified the neck, shoulders, upper limbs and ankles as the most prevalent diseases in the industry $[3,4,6,7,8,9]$. These disorders were mostly identified among female workers involved in work tasks-requiring forceful movements of the upper limbs-with repetitive movement of the arms and the hands. Other risk factors for musculoskeletal disorders identified in the industry included poor relationship with work mates, length of employment, gender, age, anthropometry, inadequate rest period, strenuous and awkward postures and manual material handling $[1,3,4,8$, $10,11,12,13,14]$.

Varieties of assessment methodologies have been used in the industry. This includes

The author wishes to acknowledge the financial support from the Swedish Institute (Stockholm, Sweden) and contribution from Dr. Barbara Richardson, Dr. Eric Kwei and Dr. Emma-Christin Lönnroth.

Correspondence and requests for offprints should be sent to Reginald Quansah, Institute of Occupational and Environmental Medicine, University of Birmingham, Edgbaston, Birmingham B15 2TT, UK. E-mail: <yaw121@yahoo.co.uk>. 
administration of a questionnaire [1, 4] or a laboratory-based study [15], or a review of company and national data [3], or the use of a checklist $[8,9]$. A combination of methods (the use of a questionnaire and physical examination) has been used in some studies [2, 6]. Babski-Reeves and Crumpton-Young [16] and Babski-Reeves [17] used continuous exposure data to characterize the interaction of a variety of risk factors. Chiang et al. [5] also combined a structured interview, physical examination and job analysis. Job analysis allows detailed investigation of a task and thus identifies the risk element in the task. However, Chiang et al.'s study involved several different groups, which prevented detailed investigation of any particular task.

In this study, I concentrated on one particular group (fish trimmers) to allow detailed investigation of how workers interact with each element of the task. The overall aim was to use a combination of methods (task analysis, walk through observation, interviews, questionnaire administration and the Rapid Upper Limb Assessment) to describe the prevalence of musculoskeletal symptoms and also to describe how workers interact with each element of their task. This was necessary because in Ghana (as against similar studies in other countries) every aspect of the task performed by fish trimmers was done manually. The specific objectives include:

1. To describe the prevalence and pattern of musculoskeletal symptoms,

2. To identify the most prominent musculoskeletal symptoms,

3. To analysis posture(s) adopted in fish trimming,

4. To identify operation(s) presenting the highest risk,

5. To identify the most problematic posture(s),

6. To provide recommendation for improvement of fish trimming.

\section{STUDY DESIGN AND METHODS}

\subsection{Study Participants}

This descriptive study was carried out in a foodprocessing factory in Tema (an industrialized city in Ghana), which produces canned tuna. This industry had about 1,500 work force of which the majority were females. Although the female population was assigned to different tasks, the nature and characteristics of their tasks were similar. The study was limited to fish trimmers following the management's complaints about recent increases in absenteeism. The trimmers constituted about one third of the total work force but at the time of the study about 200 were present (for the rest some were either sick or on leave or absent for other reasons). Some of the results can be found in Quansah [18].

Fifty out of the 200 fish trimmers present at the time of the study participated in this study and successfully completed and submitted their questionnaires (response rate 100\%). The mean height (range), mean age (range), mean weight (range) and mean length of service (range) of the participants were $159 \pm 13.8 \mathrm{~cm}(140-185)$, $37 \pm 12.5$ years $(20-48), 68 \pm 13.9 \mathrm{~kg}$ (56-95), $7 \pm 2.3$ years (3-13) respectively. The level of education of the participants was as follows: middle school-19 (38\%), form five/junior secondary school-19 (38\%), and sixth form/ senior secondary school-12 (24\%). Participants on the average worked $48 \pm 10.5 \mathrm{hrs} /$ week (range: 45-51). All 50 participants worked 8 hrs a day including a half-hour lunch break. Supervisors selected 3 or 6 participants at a time to take part in the study when they believed their absence would not affect the work process.

\subsection{Process and Task Description}

Fish trimmers are made up of skinners and polishers. Trimming is done in teams with each team constituting one skinner and two polishers standing on either sides of a workbench facing one another. The task is monotonous, repetitive and performed in standing posture. There were about four benches in use at the time of the study 
(sometimes they use 5 or 6 benches) with each bench on average accomodating 50 fish trimmers. Each trimming team has a target of producing at least 60 trays $(120 \times 130 \times 5 \mathrm{~cm})$ of loins per day. To start with, fish carriers unload trays of fish (tuna) in front of the skinners (an unskinned fish weighs between 3 and $6 \mathrm{~kg}$ ). The skinner picks up the fish and removes the scales, head pieces and fins. The skinner then passes on the skinned fish to a polisher on the opposite side of the bench. The polisher splits the fish, removes any remaining skin/scales, blood meat and cartilages. She puts the flakes from the fish into a flake tray and the remaining portion of the fish (i.e., the loins), into the loin tray on the bench. After each skinning or polishing, the trimmers push the waste ensuing from their activity into a waste conveyor belt under the bench, which carries the waste away.

\subsection{Data Collection}

Different techniques were used to collect data: questionnaires, a walk through observation, interviews and task analysis, posture evaluation and a future workshop.

\subsubsection{Questionnaire administration}

The prevalence of musculoskeletal symptoms was measured with a modified Nordic Questionnaire [19]. Psychological demand on the job, job control, supervisor and co-worker support were also investigated with the Job Content Questionnaire $[20,21]$. Sets of questions were included to collect employment and personal data. The questionnaires were despatched to participants in a conference room after the purpose of the study had been explained to them. Each subject who finished her questionnaire was asked to write her name, her job title and the section she worked in, which was to eliminate double participation (because it was noticed that workers from other section/departments wanting to take a break could take part in the exercise). This allowed elimination of a questionnaire of one worker from another department, who took part in the exercise. On average, it took the participants $10 \mathrm{~min}$ to complete the questionnaire.

\subsubsection{Walk through observation, interview and task analysis}

A walk through observation was carried out after permission had been sought from the management. This was followed with an interview with a supervisor and a worker to understand the work process, operations involved in the task, and to study various working techniques adopted by the workers. Hierarchical task analysis [22] was developed to identify various operations involved in the task performed by the participants (results not published here, see Quansah [18]). The result was later discussed with supervisors and workers to ensure inclusion of all relevant operations. Eleven operations were identified for skinners and 12 for polishers for posture analysis (Tables 5 and 6).

\subsubsection{Posture evaluation}

The names provided on the questionnaires by participants (see section 2.3.1.) were used to randomly select 20 trimmers from the 50 who had answered the questionnaire. The personal data of those 20 did not differ much from those of the $50(p<.05)$. The personal details of the 20 participants were as follows: mean height (range), mean age (range), mean weight (range) and mean length of service (range) of fish trimmers were $150 \pm 11.5 \mathrm{~cm}$ (140-187), $35 \pm 10.1$ years (26-48), $60 \pm 11.2 \mathrm{~kg}(55-89), 6 \pm 2.5$ years $(4-10)$ respectively.

As participants went about their daily routine work, their postures were recorded with the Rapid Upper Limb Assessment (RULA) [23]. The postures of each participant was recorded either twice or once in the morning (between 7.30 and 9.30 a.m.) and twice or once in the afternoon after the lunch break (between 1.30 and 4.00 p.m.) when they were busy and were not aware that their postures were recorded. Thirty-three postures were recorded for skinners and 35 for polishers. However, consideration was given only to postures with posture codes appearing more than once (they were assumed to be held for the longest time or by most subjects) and those with higher codes (they were assumed to be the postures where the highest load was likely to 
occur). The postures of the polishers and skinners were reduced to 21 each.

\subsection{Statistical Analysis}

All categorical answers of participants were entered into MS-Excel with encoded numerical values. Means and standard deviations were used to describe the demographic data such as age, level of education and marital status. The Pearson chi-square was used to indicate the differences in musculoskeletal symptoms by demographic details with the significance level at $p=.05$. The Pearson correlation was also used to investigate the relationship between participants' personal profile and musculoskeletal symptoms and the psychosocial work factors. The Pearson correlation was further used to investigate the association between the psychosocial work factors and musculoskeletal symptoms. Data analyses were performed with the SPSS version 10.0.1 software.

\section{RESULTS AND DISCUSSIONS}

This study shows that fish trimming is evidently a risk factor for musculoskeletal symptoms as reported in earlier studies [6,7]. Absence from work due to musculoskeletal discomforts was prevalent, especially for the neck and shoulder regions (Table 1). However, little attention or none at all seemed to be paid by the management about this problem. This is because musculoskeletal disorders are not yet on the occupational disease list of managements. Moreover, the management and workers seem not to acknowledge the workrelatedness of musculoskeletal symptoms.

Musculoskeletal symptoms were prevalent in the neck, the shoulders, the low back, the wrists/ hands, and ankles/feet regions (Table 1).

Musculoskeletal symptoms in the low back, the knees and the ankles (Table 1) were due to prolonged standing (for $7 \frac{1}{2} \mathrm{hrs} /$ day) with little or no rest and repetitive flexion of the back (Tables 5 and 6). Prolonged standing either restricts blood flow in the lower limbs or results in spinal loading of the low back. This confirms previous evidence that work tasks that predispose workers to stand for $25-50 \%$ of the working day ( $8 \mathrm{hrs}$ ) may lead to disorders of the low back, feet and legs [24, 25, 26, 27, 28]. Workbenches were also congested and allowed no opportunity for workers to alter their postures.

Prevalence of the neck and shoulder discomforts confirms previous Scandinavian and Taiwanese reports among similar work groups $[2,5,6]$. The causes of the pains and aches of the neck and shoulders in this study were due to inappropriate working height causing cramped, hunched shoulders. The work task was also such that workers had to extend their arms repeatedly to sustain 2 or $6 \mathrm{~kg}$ of fish with their arms maintained statically at an angle of about $45^{\circ}$ from the vertical. Such postures could create a long lasting load on the glenohumeral joint leading to muscle fatigue, pains and aches in the neck and shoulder regions $[29,30]$. Neck side bending was also predominant in operations that lasted longer (Tables 5 and 6). Neck flexion $\left(20^{\circ}\right)$ observed in this study was also greater than reported in a Swedish study [6].

TABLE 1. Prevalence of Musculoskeletal Symptoms in Nine Body Regions Among Fish Trimmers $(N=50)$

\begin{tabular}{lccc}
\hline Body Regions & In the Past 3 Months & In the Past 7 days & Unable to Work \\
$\boldsymbol{n}(\%)$ & $\boldsymbol{n}(\%)$ & $28(56.0)$ \\
Neck & $35(70.0)$ & $17(34.0)$ & $28(56.0)$ \\
Shoulders & $35(70.0)$ & $17(34.0)$ & $22(44.0)$ \\
Elbows & $20(38.0)$ & $16(32.0)$ & $20(40.0)$ \\
Wrists/hands & $32(64.0)$ & $16(32.0)$ & $19(38.0)$ \\
Upper back & $19(38.0)$ & $12(24.0)$ & $19(38.0)$ \\
Low back & $32(64.0)$ & $25(50.0)$ & $20(40.0)$ \\
Hips/thighs & $24(48.0)$ & $13(26.0)$ & $17(37.7)$ \\
Knees & $25(50.0)$ & $14(28.0)$ & $18(36.0)$ \\
Ankles/feet & $28(54.0)$ & $13(26.0)$ & \\
\hline
\end{tabular}


High prevalence of musculoskeletal symptoms in the wrists/hands confirms previous evidence that these kinds of symptoms were common in work tasks requiring fast and repetitive movement of the hands [2]. A walking through observation also showed that workers gathered waste (from skinning/polishing activities) on the bench and pushed it into holes with ulna or radially deviated wrists. Such wrist postures could also account for the disorders in the wrists [30]. It was also observed that participants exerted higher force on the knife to split fish (especially big fish) even with deviated wrist postures. Job tasks with high force components and deviated wrists have also been reported to cause disorders in the wrists [16, 31].

Except for disorders in the neck, shoulders and ankles/feet, musculoskeletal symptoms in the past 3 months were significantly higher $(p<.05)$ among the lower age group (Table 2). This was in contrast to other studies $[2,6]$. The reason is that the company in this study had a promotion scheme where workers who became older on the job were promoted to the status of table heads (overseeing fish trimming). Thus, such workers were not actively involved in fish trimming and were not exposed to the same level of load as young adult workers. The hectic nature of the task also suggests that some older workers could retire early to concentrate on income generating activities at home, leaving behind the young adult worker's "healthy worker effect".

TABLE 2. Prevalence of Musculoskeletal Symptoms in the Past 3 Months by Age Among Fish Trimmers $(N=50)$

\begin{tabular}{lrrc}
\hline & \multicolumn{3}{c}{ Age of Fish Trimmers (years) } \\
\cline { 2 - 4 } & $\mathbf{1 8 - 3 0}$ & $\mathbf{3 1 - 4 0}$ & $\mathbf{4 1 - 5 0}$ \\
Body Regions & $\boldsymbol{n}(\%)$ & $\boldsymbol{n}(\%)$ & $\boldsymbol{n}(\%)$ \\
\hline Neck & $16(64.0)$ & $9(69.2)$ & $9(75.0)^{n s}$ \\
Shoulders & $21(84.0)$ & $10(77.0)$ & $5(58.4)^{n s}$ \\
Wrists/hands & $14(56.0)$ & $8(61.6)$ & $10(83.3)^{*}$ \\
Low back & $17(68.0)$ & $7(53.4)$ & $7(58.3)^{\star}$ \\
Knees & $13(52.0)$ & $5(38.5)$ & $7(88.3)^{*}$ \\
Ankles/feet & $13(52.0)$ & $10(76.9)$ & $5(41.6)^{n s}$ \\
\hline
\end{tabular}

Notes. *-significant, $p<.05, N=50$.

Studies elsewhere among similar groups have suggested high musculoskeletal symptoms among workers who have suffered long exposure following long years of service [2, 5]. A similar observation was noted in this study, which was significantly higher $(p<.05)$ for most body regions (Table 3). It is suggested in this study that the high level of ignorance, poor working techniques, and lack of training among the workers may have aggravate their vulnerability to injuries as workers on the average had been involved in these tasks for $7 \pm 2.3$ years.

TABLE 3. Prevalence of Musculoskeletal Symptoms in the Past 3 Months by Length of Service Among Fish Trimmers

\begin{tabular}{|c|c|c|c|}
\hline \multirow[b]{2}{*}{ Body Regions } & \multicolumn{3}{|c|}{ Length of Service (years) } \\
\hline & $\begin{array}{c}<5 \\
n(\%)\end{array}$ & $\begin{array}{l}5-10 \\
n(\%)\end{array}$ & $\begin{array}{c}\geq 11 \\
n(\%)\end{array}$ \\
\hline Neck & $5(61.2)$ & $17(70.8)$ & $8(66.8)^{n s}$ \\
\hline Shoulders & $11(84.8)$ & $18(75.0)$ & $9(70.0)^{n s}$ \\
\hline Wrists/hands & $9(69.2)$ & $6(46.2)$ & $6(41.8)^{*}$ \\
\hline Low back & $9(69.2)$ & $7(58.4)$ & $7(58.4)^{*}$ \\
\hline Knees & $4(38.8)$ & $13(54.2)$ & $7(58.4)^{*}$ \\
\hline Ankles/feet & $5(38.6)$ & $10(62.2)$ & $7(58.4)^{*}$ \\
\hline
\end{tabular}

Notes. *-significant, $p<.05, N=50$.

Musculoskeletal symptoms were significantly higher $(p<.05)$ among married than single workers (Table 4). This observation can be explained by the fact that married workers have several non-occupational responsibilities such as cleaning/washing, taking care of husbands and children, etc., which exposes them to several and more ergonomic stressors than their counterparts. In this study, single workers tended to have fewer children (1 or 2) who attended high schools (results published elsewhere, see Quansah [18]). Single workers were also reluctant to bear more children for fear of work overload at home. However, the situation was different among married workers, as

TABLE 4. Prevalence of Musculoskeletal Symptoms in the Past 3 Months by Marital Status Among Fish Trimmers

\begin{tabular}{lcc}
\hline & \multicolumn{2}{c}{ Marital Status } \\
\cline { 2 - 3 } Body Regions & $\begin{array}{c}\text { Married } \\
\boldsymbol{n}(\%)\end{array}$ & $\begin{array}{c}\text { Single } \\
\boldsymbol{n}(\%)\end{array}$ \\
\hline Neck & $20(76.9)$ & $16(66.7)^{n s}$ \\
Shoulders & $23(88.5)$ & $15(62.6)^{n s}$ \\
Wrists/hands & $23(88.5)$ & $16(66.7)^{\star}$ \\
Low back & $16(61.5)$ & $15(62.6)^{\star}$ \\
Knees & $15(57.7)$ & $10(41.7)^{\star}$ \\
Ankles/feet & $16(61.5)$ & $12(50.0)^{\star}$ \\
\hline
\end{tabular}

Notes. *-significant, $p<.05, N=50$. 


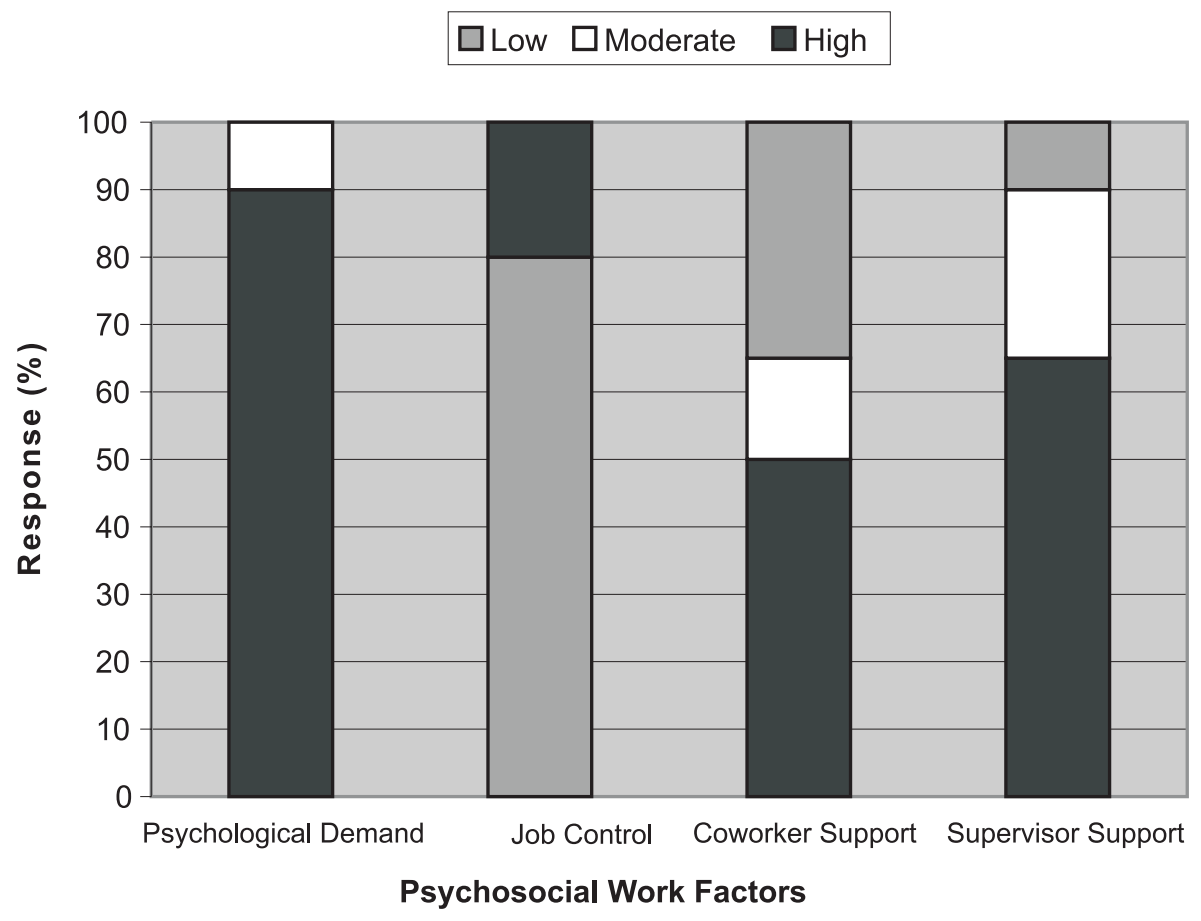

Figure 1. Response to psychosocial work factors (\%).

most were willing to have more than 3 children with the view that at least one may become successful in life in the future.

Several aspects of workplace design and work conditions were noted as exacerbating factors for musculoskeletal symptoms: the low height of workstations meant tall workers adopted postures with severe neck and back flexion, likely to contribute to neck, shoulder and low back pains. Workers also worked in the cold with little protection and in a noisy environment with no ear protectors, which could be a hazard for pains and disorders of the upper limbs. Poor lightning conditions may also result in adopting constrained neck postures for the performance of many jobs. Nordander et al. [2] reported a poor relationship with supervisors. However in this study a high psychological demand on the job and low control over the job were noted (Figure 1).

No statistically significant correlation was found between musculoskeletal symptoms and age, average working hours/week, marital status and length of service on the one hand and these factors and the psychosocial work factors on the other $(p<05)$. Neither was there any significant correlation established between musculoskeletal symptoms and psychosocial work factors $(p<.05)$.

Of the 11 operations identified with skinning, only one was considered not to require a redesign measure (i.e., skinning fish on the bench) (Table 5). For the remaining redesign measures were very necessary. Among polishers, only two operations did not require redesign measures (i.e., splitting skinned fish and removal of blood meat) (Table 6).

High risk postures such as neck flexion and neck side bending, abducted arms, repetitive reaching forward, shoulder elevation, wrist deviation, torso flexion and working below or above waist level were common. Many of these high risk postures were due to the design of the workplace and workplace layout. In most cases, tall and short workers adjusted to the workbenches by either flexing their back or adopting a combination of awkward postures to perform the task. Adoption of these awkward postures is suggested to be exacerbated by the high pace of the work following the high daily target of 60 trays of loins and poor lightning conditions. Some workers also complained of suffering severe body pains following prolonged standing. 
TABLE 5. Working Postures Noted for Operations Performed by Skinners Investigated With RULA $(N=10)$

\section{Operation}

1. Picking fish

2. Breaking head of fish

a. on the bench

b. in the hand

3. Skinned head

4. Putting head piece into head piece tray

5. Gathering waste

6. Pushing waste into hole

7. Picking other piece of fish

8. Skinning other piece in hand

9. Passing on skinned fish to a skinner

10. Gathering waste

11. Pushing waste into hole
Risk Associated With Operations

Prolonged standing on hard floor, neck side bending, abducted arms, shoulder elevation, torso flexion, wrist deviated and bent away from midline

Prolonged standing on hard floor, neck side bending, abducted arms, wrist deviation

Prolonged standing on hard floor, torso flexion, neck side bending, holding weight of $6 \mathrm{~kg}$, shoulder elevation, wrist deviation, abducted arms

Prolonged standing on hard floor, neck flexion and side bending, holding weight of $2 \mathrm{~kg}$, shoulder elevation, wrist deviated from midline

Torso flexion, prolonged standing on hard floor, working above waist level, repetitive reaching forward, abducted arms, shoulder elevation

Prolonged standing on hard floor, wrist deviation, abducted arms, shoulder elevation, repetitive bending, as soon as possible reaching forward, neck flexion, side bending

Torso flexion, prolonged standing on hard floor, neck side bending, working above waist level, shoulder elevation, repetitive reaching forward, abducted arms

Standing on hard floor, neck side bending, abducted arms, shoulder elevation

Prolonged standing on hard floor, torso flexion, abducted arms, neck side bending, holding weight of $4 \mathrm{~kg}$, shoulder elevation, working above waist level

Prolonged standing on hard floor, torso flexion, holding fish (weight of $4 \mathrm{~kg}$ ), shoulder elevation, working above shoulder level

Standing on hard floor, neck flexion, side bending, abducted arms, shoulder elevation, repetitive reaching forward, wrist deviated, working across midline of the body

Prolonged standing on hard floor, torso flexion, neck side bending, shoulder elevation, working above waist level

TABLE 6. Working Postures Noted for Operations Performed by Polishers Investigated With RULA $(N=10)$

\section{Operation}

1. Picking skinned fish

2. Splitting skinned fish

3. Removal of blood meat

4. Putting flakes into polishing tray

5. Putting loins into tray when tray on pallet*

6. Gathering waste

7. Putting waste into hole

Risk Associated With Operations

Prolonged standing on hard floor, neck side bending, abducted arms, shoulder elevation, torso flexion, wrist deviated and bent away

Prolonged standing on hard floor, neck side bending, abducted arms, shoulder elevation, wrist deviated and twisted

Prolonged standing on hard floor, neck side bending, abducted arms, shoulder elevation

Standing on hard floor, neck side bending, abducted arms, shoulder elevation, repetitive reaching forward

Prolonged standing on hard floor, neck side bending, abducted arms, shoulder elevation, torso flexion

Standing on hard floor, neck flexion and side bending, repetitive reaching forward, torso flexion, wrist deviated and bent away, working across midline of body

Standing on hard floor, neck side bending, abducted arms, torso flexion, wrist deviation, repetitive reaching forward, wrist deviation

Notes. *-when polishers reach 5 , they go back to start from 1 down to 7. 
The method applied in this study is appropriate for any industrial setting. It is not only relevant in increasing an understanding of how the tasks interact with workers, but also in promoting ergonomic knowledge at the workplace. Following the company's policy, which forbids the use of any photographic material on the production floor, pen and paper for the posture analysis was preferred to video technique in this study. The observer being aware of potential observer errors, carefully followed subjects and recorded their postures when they were busy with their work and were not aware that their postures were recorded. Thus, it could be argued that observation bias was reduced to the barest minimum.

One source of error inherent in this study, which goes with modern complex production environments, was selection bias: (a) the subjects selected by supervisors might have represented those who were less likely to report unfavourable work situation, and (b) knowledge among subjects that the management knew about their participation in the study may have also influenced their objectivity regarding their answers to the questionnaire. Also the use of pen and paper may have allowed fast postures to be overlooked. However, it could be argued that the observer being aware of this carefully followed the operations. Thus, it could be said that most postures adopted for the greater part of the time were captured.

\section{CONCLUSIONS AND RECOMMENDATIONS}

The results of this study show that fish trimming created high postural load on workers' musculoskeletal systems, particularly in the neck, the shoulders, the low back, the wrists/hands, and the ankles/feet. Poor working postures were related to a poor design of the work place, poor working techniques, lack of training, ignorance and lack of supervision. Major ergonomic intervention is thus necessary to improve the work conditions, work place and the task. This may require active work place participation. Some feasible improvements in the working condition were recommended:
- Decongesting work benches to allow free mobility and to provide space for the loin trays on the work bench instead of the pallet on the bench.

- Provision of an adjustable platform to accommodate all categories of workers (both tall and short).

- Workers should be trained on appropriate and safe working methods and techniques.

- Provision of an adjustable sit/stand stool with foot rest to provide support for workers' weight but still to keep them in an appropriate position to perform the task.

- Provision of standard rubber mats to reduce aches in the lower limbs.

- Introduction of micropauses during work to allow muscles to recuperate.

- Provision of arm support for workers during skinning/polishing.

\section{REFERENCES}

1. Messing K, Reveret JP. Are women in female jobs for health? A study of working conditions and health effects in the fish processing industry in Quebec. Int J Health Serv 1983;13(4):635-48.

2. Nordander $\mathrm{C}$, Ohlsson $\mathrm{K}$, Balogh $\mathrm{I}$, Rylander L, Pålsson B, Skerfving S. Fish processing work: the impact of two sex dependent exposure profiles on musculoskeletal health. Occup Environ Med 1999;56:256-64.

3. Palsson B, Stromberg U, Ohlsson K, Skerfving $S$. Absence attributed to incapacity and occupational disease/ accidents among female and male workers in the fish processing industry. Occup Med 1998;48(5):289-95.

4. Olafsdottir H., Rafnsson V. Increase in musculoskeletal symptoms of upper limbs among women after introduction of the flow-line in fish-fillet plants. Int J Ind Ergon 1998;21 (1):69-77.

5. Chiang H, Ko $\mathrm{Y}$, Chen $\mathrm{S}, \mathrm{Yu} \mathrm{H}, \mathrm{Wu} \mathrm{T}$, Chang P. Prevalence of shoulder and upperlimb disorders among workers in the fishprocessing industry. Scand J Work Environ Health 1993;19(2):126-31. 
6. Ohlsson K, Hansson GA, Balogh I, Stromberg U, Palsson B, Nordander C, et al. Disorders of the neck and upper limbs in women in the fish processing industry. Occup Environ Med 1994;51:826-32.

7. Hasvold T. Headache and neck or shoulder pain (ISM serial No. 38). Tromsø, Norway: Institute of Community Medicine, University of Tromsø; 1996.

8 Fairfax R. Ergonomic hazards in the fish processing industry-part I. Appl Occup Environ Hyg 1997;12(4):245-9.

9. Golias E, Motley K, Fairfax R. Ergonomic hazards in the fish processing industrypart II. Appl Occup Environ Hyg 1997;12(4):329-35.

10. Golias E, Motley K, Fairfax R. Ergonomic hazards in the fish processing industrypart III. Appl Occup Environ Hyg 1997;12(6):400-6.

11. Corlett E.N., Manenica I. The effects and measurement of working postures. Appl Ergon 1980;11:7-16.

12. Garg A, Moore JS. Prevention strategies and the low back in industry. J Occup Med 1992;7:629-40.

13. Björksten $\mathrm{MG}$, Boquist $\mathrm{M}$, Edling $\mathrm{C}$. Reported neck and shoulder problems in female industrial workers: the importance of factors at work and at home. Int J Ind Ergon 2001;27(3):159-70.

14. Cox T, Mackay CJ. The impact of repetitive work and self-reported mood. Journal of Occupational Behaviour 1979;3:247-52.

15. Madeleine $\mathrm{P}$, Lundager B, Voigt M, ArendtNielsen L. The effects of neck-shoulder pain development on sensory-motor interactions among female workers in the poultry and fish industries. A prospective study. Int Arch Occup Environ Health 2003;76(1):39-49.

16. Babski-Reeves $\mathrm{K}$, Crumpton-Young L. The use of continuous exposure data for predicting CTS in fish processing operators. Ergonomics 2003;46(7):747-9.

17. Babski-Reeves K. Quantification of the exposure-response relationships of the primary risk factors for carpal tunnel syndrome [doctoral dissertation]. Starkville, MS, USA: Mississippi State University; 2000.
18. Quansah, R. Ergonomic job analysis: identification of musculoskeletal disorders among selected workers of a fish processing factory in Ghana [master thesis]. Luleå, Sweden: Luleå University of Technology; 2003.

19. Kuorinka I, Jonsson B, Kilbom A,, Vinterberg H, Biering-Sørensen F. Standardized Nordic Questionnaire for the analysis of musculoskeletal symptoms. Appl Ergon 1987;18:233-7.

20. Karasek RA. Job demands, job decision latitude, and mental strain: implications for job redesign. Administration Science Quarterly 1979;24:285-307.

21. Karasek R, Theorell T. Healthy work: stress, productivity, and the reconstruction of working life. New York, NY, USA: Basic Books; 1990.

22. Shepherd, A. Analysis and training of information technology tasks. In: Diaper D, editor. Task analysis for human computer interaction, Chichester, UK: Ellis Harwood; 1989. p. 15-54.

23. McAtamney L, Corlett EN. RULA: a survey method for investigation of workrelated upper limb disorders. Appl Ergon 1993;24(2):91-9.

24. Ryan GA. The prevalence of musculoskeletal symptoms in supermarket workers. Ergonomics 1989;32:359-71.

25. Rys M, Konz S. Standing. Ergonomics 1994;37(4):677-87.

26. Rys M, Konz S. Floor mats. Count down to the 21st century. In: Proceedings of Human Factors Society, 34th annual meeting, Orlando, Florida, October 8-12. Santa Monica, CA, USA: Human Factors Society; 1990. vol 1:1. p. 575-79.

27. Buckle PW, Stubbs DA, Baty D. (1986). Musculoskeletal disorders (and discomfort) associated factors. In: Corlett N, Wilson J, Manenica I, editors. Proceedings of the International Conference on Working Postures, Zadar, Yugoslavia. London, UK: Taylor \& Francis; 1986. p. 10-30.

28. Drewczynski A. Working in a standing position (Publication No. CCOHS/CCHST P88-14E). Hamilton, Ont., Canada: Canadian Centre for Occupational Health and Safety; 1988. 
29. Mathiassen SE, WinkleJ.Electromyographic acitivity in the shoulder-neck region according to arm position and glenohumeral torque. Eur J Appl Physiol Occup Physiol 1990;61:370-9.

30. Armstrong TJ. Upper extremity posture: definition, measurement and control. In: Corlett N, Wilson J, Manenica I, editors. Ergonomics of working posture: models, methods and cases. London, UK: Taylor \& Francis; 1986. p. 59-73.
31. Aptel M, Cail, F. An empirical index for evaluating the biomechanical wrist stress. In: Mital A, Krueger H, Kumar S, Menozzi M, Fernandez J, editors. Advances in occupational ergonomics and safety I. Cincinnati, OH, USA: International Society for Occupational Ergonomics and Safety; 1996. p. 421-6. 